\title{
Connecting Older Adults through Voice-Based Interfaces
}

Robin Brewer

Northwestern University

Evanston, IL 60660, USA

rnbrewer@u.nothwestern.edu
Permission to make digital or hard copies of part or all of this work for personal or classroom use is granted without fee provided that copies are not made or distributed for profit or commercial advantage and that copies bear this notice and the full citation on the first page. Copyrights for third-party components of this work must be honored. For all other uses, contact the Owner/Author.

Copyright is held by the owner/author(s).

CSCW '16 Companion, February 27 - March 02, 2016, San Francisco, CA, USA

ACM 978-1-4503-3950-6/16/02.

http://dx.doi.org/10.1145/2818052.2874350

\begin{abstract}
My dissertation work focuses on increasing access to online communication and enabling self-expression for older adults with vision impairments. This population experiences barriers including technology cost and learnability of accessible software required for going online. My dissertation draws on research in

accessibility, social computing, and aging along with my background in computer science, human-computer interaction, and communication studies. I will design, build, and evaluate a voice-based online platform that allows older adults to share content and express themselves through a traditional phone interface. I will study how sharing through this platform impacts social support, isolation, and quality of life as people age with vision impairments.
\end{abstract}

\section{Author Keywords}

Older adults, accessibility, communication, expression, vision impairment

\section{ACM Classification Keywords}

H.5.m. Information interfaces and presentation (e.g. $\mathrm{HCI}$ ): Miscellaneous;

\section{Introduction and Background}

Much research has described the benefits of internet use including improved information access, social 
support, and quality of life $[4,6,7]$. While $86 \%$ of the United States adult (18+) population has internet access, $41 \%$ of older adults do not use the internet at all and 53\% do not have internet access in their homes [17]. Moreover, older adults with disabilities are much less likely to use the internet $[5,8]$ primarily because of the high cost of assistive technologies that would enable their usage, and complexity of learning how to use these technologies $[10,18]$. However internet use, especially amongst marginalized populations has been shown to provide many benefits such as a supportive community and improved quality of life $[4,5,8]$.

One specific population for whom internet use is particularly challenging is older adults with vision impairments. Over 11 million older adults face significant age-related vision loss (e.g., macular degeneration, glaucoma) in the United States alone, and this number is projected to double by 2050 [16]. Therefore I seek to understand how to design information communication technologies (ICT) that make it easier for older adults with vision impairments to communicate and express themselves online. My research questions are 1 ) how can researchers design communication technologies to encourage older adults to be active in today's online culture, thus benefitting from internet use and 2) how does such technology affect social support, isolation, and quality of life of these older adults?

\section{Prior Work}

To begin to understand how to answer the first question, I conducted interviews with older adults to explore how they communicate online and offline. From these interviews and other research $[9,12]$, I learned of the importance of phone communication and their desire to be able to communicate with family members and friends online. Because of these findings and the prevalence of e-mail communication among older adults who are currently active online [19], I began to investigate how to a design a voice-based messaging platform that embedded email into a familiar platform [12] - landline phones.

After researching other forms of voice-based platforms I learned that the research community was divided on how these systems should be designed for older adults $[11,13]$. Therefore I developed a prototype with limited features of a phone e-mail system and conducted a $2 \times 2 \times 2$ within-subjects prototype testing study to understand the best gender, pitch, and speed for voicebased interfaces for seniors. From this study, I learned that the ideal system should use a male, low pitch voice [1] and incorporated these findings into the development of a higher fidelity system which older adults used in their homes to email family members and friends for four weeks. The findings showed the success of embedding directed communication in the form of email for older adults, particularly if they are unable to access computers but have a desire to express themselves online.

Prior work highlights that one population with low access to computers and the Internet are people with vision impairments who face a unique set of accessibility challenges including learnability and cost $[10,18]$. It is important to note that Therefore, my future work focuses on how the familiarity and low-cost 
of phone-based online platforms could help this growing demographic to communicate online.

To investigate how older adults with vision impairments communicate both online and offline, I conducted interviews with 20 older adults who were low vision or legally blind. Although we envisioned these older adults to be a potential user group of our voice-based messaging system, our informants typically communicated with very few social contacts and learning to use and accessing the internet remained a significant challenge $[10,18]$. Rather, older adults with vision impairments understood the value of going online and wanted to gain new hobbies by engaging in discussion online [14].

Prior studies note that blogging provides an important form of online self-expression and enables discussion for younger people $[2,15]$. Through a recent study with 20 older adult bloggers (all sighted) I found that blogging provides older adults with a community of peer social support, meaningful work post-retirement, and opportunities for self-expression and identity development [under review]. Hence, a voice-based blogging platform may be an accessible and meaningful way of engaging older adults with vision impairments in online communication and self-expression.

\section{Work in Progress}

Building on findings from my prior work [1], I have begun to develop a voice-based blogging platform that integrates Twilio, Python, PHP, and the Tumblr API. Older adults can dial a number on a phone of their choice (e.g. landline phone, non-smart cell phone) and record a blog post which gets posted to Tumblr, listen to comments made by people online (e.g. computer, smart mobile device), and listen to blog posts of their peers. My future work includes 1) continuing development of the system, 2) testing its usability, and 3 ) evaluating its long-term impacts on social isolation, quality of life, and social support [3].

\section{Doctoral Colloquium Participation}

As a participant in the CSCW Doctoral Colloquium, I will be able to use my experience in both social and technical fields to provide helpful feedback to my peers as well as benefit from others' feedback. By the time the colloquium takes place, I will be finalizing the system and evaluation design, which will be an ideal time for me to get feedback from the diverse group of researchers present. In particular, I invite feedback on methodological design including how to best analyze the data and appropriate measures to use, as well as how to frame my research in both the academic and industry domains. I am excited to also broaden my network of peers in the CSCW community.

\section{References}

1. Robin N. Brewer, Raymundo Cornejo, Ted Schwaba, Darren Gergle, and Anne Marie Piper. 2016. Exploring Traditional Phones as an E-Mail Interface for Older Adults. ACM Transactions on Accessible Computing.

2. Deborah S. Chung and Sujin Kim. Blogging activity among cancer patients and their companions: Uses, gratifications, and predictors of outcomes. Journal of the American Society for Information Science and Technology 59, 2. http://doi.org/10.1002/asi.v59:2

3. Erin York Cornwell and Linda J Waite. 2009. Social Disconnectedness, Perceived Isolation, and Health among Older Adults. Journal of Health and Social Behavior 50, 1, 31-48. http://doi.org/10.1177/002214650905000103 
4. K Dobransky and E Hargittai. 2006. The Disability Divide in Internet Access and Use. Information, Communication and Society 9, 3, 313-334.

5. Angela Edwards. Tackling digital exclusion: Older blind and partially sighted people and the internet.

6. Nb Ellison, Charles Steinfield, and Cliff Lampe. 2007 The Benefits of Facebook "Friends:" Social Capital and College Students' Use of Online Social Network Sites. Journal of Computer-Mediated Communication 12, 1143-1168. http://doi.org/10.1111/j.10836101.2007.00367.x

7. Shelly Farnham, Lili Cheng, Linda Stone, et al. 2002 HutchWorld: Clinical Study of Computer-Mediated Social Support for Cancer Patients and Their Caregivers. CHI 2002, 1, 375-382.

8. Elaine Gerber and Corinne Kirchner. 2001. Who's Surfing? Internet Access and Computer Use by Visually Impaired Youth and Adults. Journal of Visual Impairment and Blindness 95, 3, 176-181.

9. Alexis Hope, Ted Schwaba, and Anne Marie Piper. 2014. Understanding digital and material social communications for older adults. Proceedings of the 32nd annual ACM conference on Human factors in computing systems, ACM Press, 3903-3912. http://doi.org/10.1145/2556288.2557133

10. Jonathan Lazar and Paul Jaeger. 2011. Reducing barriers to online access for people with disabilities. Issues in Science and Technology 27, 2, 68-82.

11. EJ Lee, C Nass, and S Brave. 2000. Can computergenerated speech have gender?: an experimental test of gender stereotype. $\mathrm{CHI}^{\prime} \mathrm{OO}$ extended abstracts on Human factors .... Retrieved March 12, 2014 from http://dl.acm.org/citation.cfm?id=633461

12. Siân E Lindley, Richard Harper, and Abigail Sellen. 2009. Desiring to be in touch in a changing communications landscape. Proceedings of the 27th international conference on Human factors in computing systems - CHI 09, ACM Press, 1693. http://doi.org/10.1145/1518701.1518962

13. L Lines and KS Hone. 2002. Older adults' evaluations of speech output. Proceedings of the fifth international ACM conference .... Retrieved March 12, 2014 from http://dl.acm.org/citation.cfm?id $=638280$

14. Patrick Okonji, Monique Lhussier, Catherine Bailey, and Mima Cattan. 2015. Internet use: Perceptions and experiences of visually impaired older adults. Journal of Social Inclusion 6, 1, 120-145.

15. Anne-Marie Oostveen. 2011. The internet as an empowering technology for stigmatized groups: a case study of weight loss bloggers. Proceeding BCS-HCI '11 Proceedings of the 25th BCS Conference on HumanComputer Interaction, 114-119. Retrieved from http://dl.acm.org/citation.cfm?id=2305316.2305337

16. David B Rein, John S Wittenborn, Xinzhi Zhang, Amanda A Honeycutt, Sarah B Lesesne, and Jinan Saaddine. 2009. Forecasting age-related macular degeneration through the year 2050: the potential impact of new treatments. Archives of ophthalmology $127,4,533-40$

http://doi.org/10.1001/archophthalmol.2009.58

17. A Smith. 2014. Older Adults and Technology Use: Adoption is increasing but many seniors remain isolated from digital life. Pew Research Center.

18. Shaw Trust. 2013. Can "digital by default" be accessible?

19. Katheryn Zickuhr and Mary Madden. 2012. Older Adults and Internet Use. Retrieved from

http://pewinternet.org/Reports/2012/Older-adultsand-internet-use.aspx 